\title{
Repeating Grades in School: Current Practice and Research Evidence
}

University of Pennsylvania

Follow this and additional works at: https://repository.upenn.edu/cpre_policybriefs

Part of the Curriculum and Instruction Commons, Educational Methods Commons, and the Education Policy Commons

\section{Recommended Citation}

University of Pennsylvania. (1990). Repeating Grades in School: Current Practice and Research Evidence. CPRE Policy Briefs.

Retrieved from https://repository.upenn.edu/cpre_policybriefs/47

This document was authored by the Consortium for Policy Research in Education, but no individual authors were identified.

View on the CPRE website.

This paper is posted at ScholarlyCommons. https://repository.upenn.edu/cpre_policybriefs/47

For more information, please contact repository@pobox.upenn.edu. 


\title{
Repeating Grades in School: Current Practice and Research Evidence
}

\author{
Abstract \\ Retaining students in grade is often used as a means to raise educational standards. Many believe that \\ repeating a grade is an effective remedy for students who have failed to master basic skills. Therefore, \\ grade retention is relatively prevalent in this nation. \\ However, research on student retention indicates that it does not work as intended to assure mastery of \\ skills, avoid failure at higher grade levels and lower dropout rates. This issue of CPRE Policy Briefs is \\ based on material in a recently published book, Flunking Grades: Research and Policies on Retention \\ (London: Falmer, 1989). The book's editors, Lorrie A. Shepard and Mary Lee Smith, address a series of \\ questions abut the practice of grade retention and the research evidence. \\ Disciplines \\ Curriculum and Instruction | Educational Methods | Education Policy \\ Comments \\ This document was authored by the Consortium for Policy Research in Education, but no individual \\ authors were identified. \\ View on the CPRE website.
}




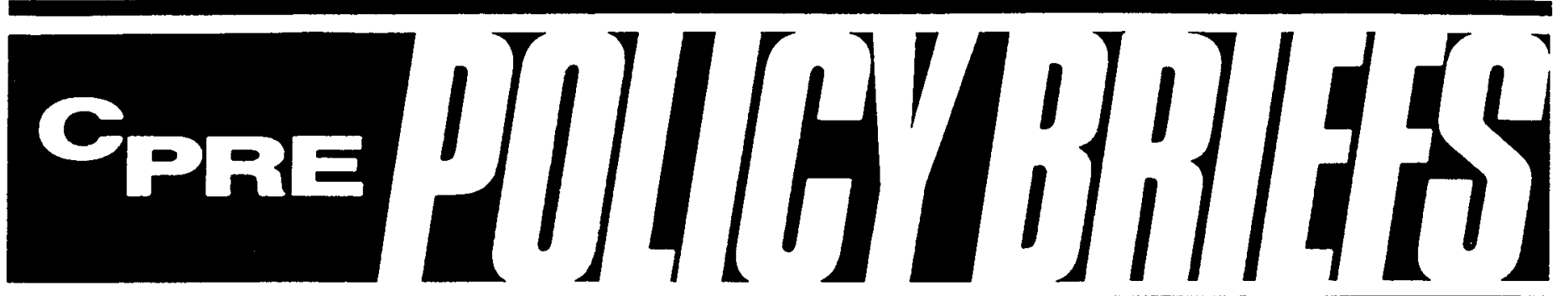

REPORTING ON ISSUES AND RESEARGH IN EDUGATION POLICY

\section{Repeating Grades in School Current Practice and Research Evidence}

Retaining students in grade is often used as a means to raise educational standards. Many believe that repeating a grade is an effective remedy for students who have failed to master basic skills. Therefore, grade retention is relatively prevalent in this nation.

However, research on student retention indicates that it does not work as intended to assure mastery of skills, avoid failure at higher grade levels and lower dropout rates. This issue of CPRE Policy Briefs is based on material in a recently published book, Flunking Grades: Research and Policies on Retention (London: Falmer, 1989). The book's editors, Lorrie A. Shepard and Mary Lee Smith, address a series of questions about the practice of grade retention and the research evidence.

\section{How prevalent is student retention in grade?}

No national statistics are collected on grade retention. Census data on the proportion of students "below modal grade" are very inaccurate because of variation among states in school entrance ages, number of children who start school late and changes in the time of year when census data are collected. Table 1 summarizes retention rates from Washington $\mathrm{DC}$ and 13 states where data were available.

It is estimated that 5 to 7 percent of public school children (about 2 children of every classroom of 30) are retained in the U.S. annually; Southern states are overrepresented in Table 1. However, annual statistics give a misleading picture. A 6 percent annual rate year after year produces a cumulative rate of nonpromotion greater than 50 percent. Even allowing for students who repeat more than one grade, by ninth grade approximately 50 percent of all students in the U. S. have flunked at least one grade (or are no longer in school).

As discussed in the sidebar on page 3, even those children just beginning school are flunking. In some districts, as many as 50 percent of children are asked to repeat kindergarten. Altogether, current grade failure rates are as high as they were in the nineteenth century, before the days of social promotion.

Also not apparent from the aggregate annual data in Table 1 are the differential retention rates by sex and ethnicity. Data from the October 1986 Current Population Survey, averaged across grades 1-12, indicate that the percentage of overage students was 31 percent for males as compared to 22 percent for females. Similarly, the percentages of overage students are much higher for African Americans and Hispanic origin students than for whites. For male students, 29 percent of whites were overage as compared to 42 percent of African Americans and 39 percent of those of Hispanic origin. These figures somewhat underrepresent actual counts of overage students because they do not include those students who dropped out before finishing high school.

A final note is that annual rates in the U.S. are also higher than in many other industrialized nations. Primary grade retention rates are 0 percent in Japan and the United Kingdom, for example, and the median rate of grade repetition for Europe and the Soviet Union is 2 percent. 
TABLE 1

\section{Percentages of Students Retained in Each Grade at the Conclusion of the 1985-86 School Year}

\begin{tabular}{|c|c|c|c|c|c|c|c|c|c|c|c|c|c|c|}
\hline State or Region & K & 1 & 2 & 3 & 4 & $\underset{5}{\text { Grade }}$ & 6 & 7 & 8 & 9 & 10 & 11 & 12 & $\begin{array}{c}\text { Total } \\
(\mathrm{K}-12)\end{array}$ \\
\hline Arizona & 8.0 & 20.0 & 8.0 & 5.0 & 4.0 & 4.0 & 4.0 & 8.0 & 7.0 & 6.0 & 3.0 & 2.0 & 14.0 & 7.2 \\
\hline Delaware & 5.4 & 17.2 & 4.9 & 2.8 & 2.3 & 3.0 & 3.2 & 9.6 & 7.7 & 15.6 & 16.8 & 8.7 & 7.5 & 8.1 \\
\hline District of Columbia & $n / a$ & 12.7 & 8.4 & 7.4 & 5.4 & 4.6 & 2.8 & 10.6 & 6.6 & $n / a$ & $n / a$ & $n / a$ & $n / a$ & 7.3 \\
\hline Florida & 10.5 & 11.2 & 4.7 & 4.5 & 3.8 & 2.6 & 3.5 & 7.9 & 5.8 & 12.1 & 11.9 & 8.9 & 3.5 & 7.2 \\
\hline Georgia & 8.0 & 12.4 & 6.7 & 7.8 & 5.2 & 3.9 & 5.3 & 6.7 & 7.5 & $\{8.1$ & 12.2 & 8.7 & 4.5 & 8.5 \\
\hline Hawaii & 2.0 & 1.6 & 1.0 & 0.7 & 0.5 & 0.4 & 0.5 & 2.1 & 2.8 & 8.9 & 6.9 & 5.5 & 0.8 & 2.6 \\
\hline Kentucky & 4.0 & 5.3 & 4.9 & 3.0 & 2.3 & 1.9 & 2.7 & 5.4 & 3.8 & 9.6 & 6.3 & 4.6 & 3.4 & 5.3 \\
\hline Maryland & $n / a$ & $n / a$ & $n / a$ & $\mathrm{n} / \mathrm{a}$ & $\mathrm{n} / \mathrm{a}$ & $\mathrm{n} / \mathrm{a}$ & $n / a$ & $\mathrm{n} / \mathrm{a}$ & $\mathrm{n} / \mathrm{a}$ & $\mathrm{n} / \mathrm{a}$ & $\mathrm{n} / \mathrm{a}$ & $n / a$ & $n / a$ & 5.5 \\
\hline Mississippi & 1.4 & 16.1 & 7.0 & 5.3 & 5.7 & 6.0 & 5.6 & 11.2 & 9.3 & 12.9 & 12.6 & 9.0 & 5.7 & 8.9 \\
\hline New Hampshire & 4.4 & 9.1 & 3.7 & 1.5 & 1.1 & 1.0 & 7.0 & 3.3 & 3.2 & 10.5 & 5.5 & 4.2 & 4.9 & 4.2 \\
\hline North Carolina & 6.0 & 9.3 & 5.0 & 5.7 & 2.7 & 2.1 & 8.1 & 7.9 & 11.0 & 13.9 & 13.2 & 9.3 & 3.9 & 7.7 \\
\hline Tennessee & 3.9 & 10.9 & 5.1 & 3.9 & 3.3 & 3.2 & 3.2 & 8.1 & 6.1 & 9.6 & 8.6 & 7.0 & 5.9 & 6.2 \\
\hline Virginia & 8.3 & 10.2 & 4.8 & 4.2 & 3.7 & 2.9 & 3.4 & 8.1 & 9.7 & 13.9 & 8.8 & 6.1 & 7.0 & 7.2 \\
\hline West Virginia & 4.4 & 7.5 & 3.3 & 2.7 & 2.3 & 2.2 & 1.8 & 4.6 & 2.5 & $n / a$ & $n / a$ & $\mathrm{n} / \mathrm{a}$ & $\mathrm{n} / \mathrm{a}$ & 3.5 \\
\hline
\end{tabular}

\section{Why is retention in grade relatively prevalent in the United States?}

Retention in grade is intended to catch students up on prerequisite skills so they are less at risk for failure when they go on to the next grade. Strict enforcement of promotion standards at every grade is expected both to ensure the competence of high school graduates and lower the dropout rate because learning deficiencies would never be allowed to accumulate.

Grade retention is very popular with the public. In a recent Gallup poll, 72 percent of the U.S. citizenry favored stricter grade-to-grade promotion standards (Gallup 1986). Such public support creates strong political pressures on schools to maintain acceptably high levels of grade retention as proof of high standards.

Furthermore, without the benefit of controlled experiments that systematically compare the performance of equally achieving students who are retained and not retained, teachers and administrators may think grade retention is successful. If a child does poorly but is promoted, his struggles in the next grade may be interpreted as evidence that he should have been retained. If a comparable child is held back and does better on the repeated material the following year, his improvement, whatever its magnitude, may be interpreted as evidence that retention works. If he does not do 2 better in the next or succeeding grades, the response may be "at least we tried" or "he would have done even more poorly without the extra year."

\section{Does repeating a grade improve student achievement?}

In a recent synthesis of research, $C$. Thomas Holmes (1989) of the University of Georgia reviewed 63 controlled studies where retained students were followed up and compared to similar students who went directly on to the next grade.

Fifty-four studies showed that when retained children went on to the next grade they actually performed more poorly on average than if they had gone on without repeating. For example, suppose that retained and control groups started out at the 10th percentile on standardized achievement tests at the end of first grade. The retained group was made to repeat first grade while the control group was promoted to second grade. Two years later when the retained children completed second grade they might be (on average) at the 20th percentile. However, the control children, would be achieving ahead of their retained counterparts by roughly .31 standard deviation units, or at roughly the 30th percentile on average.

When Holmes selected only 25 studies with the greatest amount of statistical control, the negative effect of retention was again confirmed. Indeed, only 9 studies of the entire 63 showed overall positive results, and most of these compared retained students who had received extra help through individualized programs and smaller classes to promoted control children who had not been given comparable assistance. Even so, the apparent benefits of retention tended to diminish over time so that differences in performance between retained and control children disappeared.

\section{What are the emotional effects of retention?}

Holmes' synthesis of controlled studies included nearly 50 studies with some social or emotional outcome measures. On average, retained students do more poorly than matched controls on follow-up measures of social adjustment, attitude toward school, behavioral outcomes, and attendance.

Children perceive retention as a punishment. When researcher Deborah Byrnes (1989) interviewed children and used euphemisms to refer to spending two years in the same grade, even first graders said, "Oh, you mean flunking." Eightyseven percent of the children interviewed said that being retained made them feel "sad," "bad," "upset," or "embarrassed." Only 6 percent of retained children gave positive answers about how retention made them feel like, "you learn more" or "it lets you catch up."

In a much quoted study of childhood 
stressors by Kaoru, Yamamoto (1980), children rated the prospect of repeating a grade as more stressful than "wetting in class" or being caught stealing. The only two life events that children said would be more stressful than being retained are going blind or losing a parent.

\section{Does nonpromotion prevent school dropouts?}

Researchers of the dropout phenomenon have consistently found that student retention is associated with an increased probability of dropping out, rather than the reverse. Dropouts are five times more likely to have repeated a grade than are high school graduates. Students who repeat two grades have a probability of dropping out of nearly 100 percent.

While this relationship has been documented for a long period of time, only recently have we understood that retention affects dropping out independently of achievement. Grissom and Shepard (1989) conducted three large-scale studies, involving 20,000 to 80,000 students each, where they examined the retention-dropout relation after controlling for achievement. They found that with equally poor achievement (and controlling for other background characteristics associated

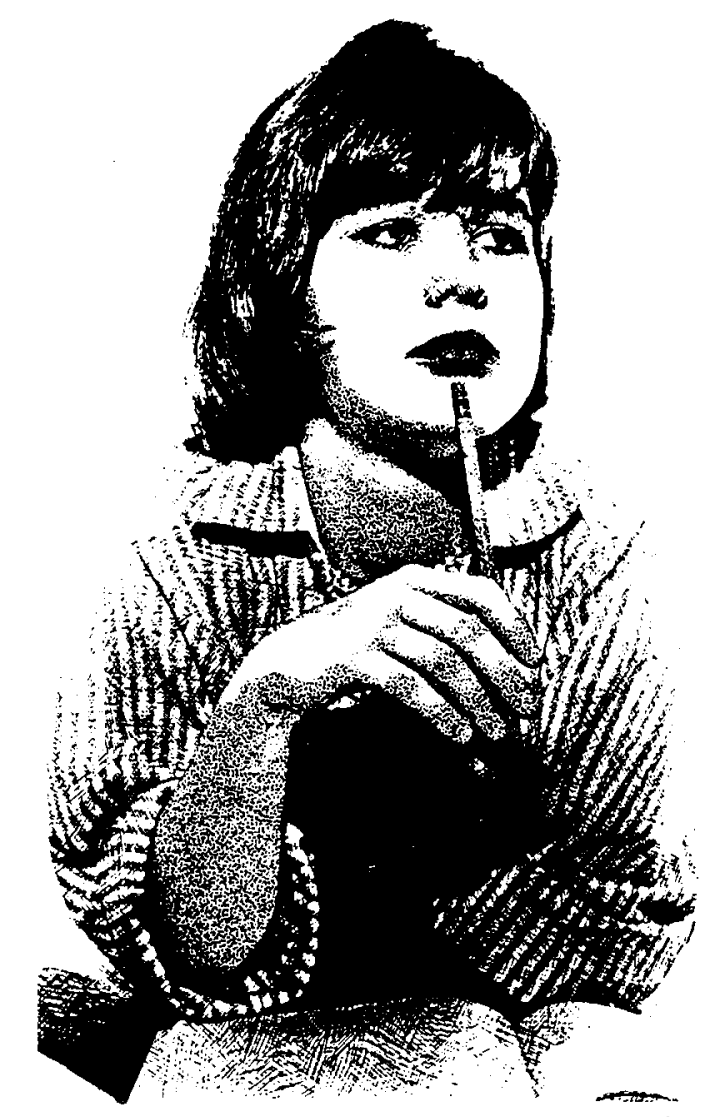

\section{The new phenomenon of kindergarten retention}

The decade of the 1980s saw a dramatic rise in the number of children asked to repeat kindergarten. In districts with special programs for "unready" kindergartners, as many as 50 percent are held back. An extra year before first grade is offered in a variety of different forms: transition classrooms before first grade, developmental kindergarten before kindergarten, and straight repeating of kindergarten. According to its advocates, kindergarten retention is different from retention in later grades because it is intended to prevent school failure before it occurs.

Controlled studies do not support the benefits claimed for extra-year programs, however, and negative side effects occur just as they do for retention in later grades. In a review of 16 controlled studies on the effects of extra-year programs, the predominant finding is one of no difference (Shepard 1989). For example, when researchers follow extra-year children to the end of first grade or as far as fifth grade and compare their performance to unready children whose parents refused the extra year, the extra-year children perform no better academically despite being a year older for their grade. The conclusion of no benefit holds true even for studies where children were selected on the basis of immaturity rather than for academic risk, and even where a special transition curriculum was offered rather than repeating kindergarten.

\section{Although the majority of teachers} believe that retention in kindergarten does not carry a social stigma "if handled properly," extra-year children are more likely to have lower self-concepts and poorer attitudes toward school compared to con- trols. Parent interviews reveal both short-term and long-term distress associated with the retention decision (teasing by peers and tears because friends are going on; references years later such as, "If I had only been able... I would be in third grade now.")

Various analysts have suggested that kindergarten retention is an educational fad, gaining popularity because of the apparent need to remove unready children from increasingly narrow academic demands in kindergarten and first grade. Long periods of seat work, worksheets, and coloring inside the lines are required of children. These demands are inconsistent with the normal development of 5 and 6 years olds.

Although these trends might have originated because schools wanted to teach more, inappropriate curriculum has actually resulted in children learning less. For example, kindergartners can solve addition and subtraction problems if they are given blocks or beads to count, but will fail if expected to learn from flash cards. Young children, however bright, are in a concrete stage of learning and are not ready for symbolic representations.

Numerous national associations have issued policy statements calling for more developmentally appropriate curriculum in early grades and reform of harmful instructional practices. These organizations include The National Association for the Education of Young Children, National Association of State Board's of Education, Association for Childhood Education International, Association for Supervision and Curriculum Development, International Reading Association, National Association of Elementary School Principals and the National Council of Teachers of English. with dropping out), students who repeated a year were 20 to 30 percent more likely to drop out of school. For example, in Austin, Texas, males of African-American origin with below average achievement have a 45 percent chance of dropping out of school; but males of the same origin and identical achievement scores who have repeated a year of school have a 75 percent chance of leaving school before graduation. A substantially increased risk for dropping out after repeating a grade was found even in a large affluent suburban school district with only a 4 percent dropout rate. The evidence is clear: school policies meant to raise the 
number of grade retentions will more likely increase rather than reduce school dropout rates.

\section{Why does retention in grade fail to improve performance and provent dropping out?}

Researchers have not been able to tell why retention doesn't work as intended. Some have speculated that the negative emotional effects of repeating harm subsequent learning. Others have suggested that going through the same material again is a crude and ineffective way to individualize instruction since a child may be more than one year behind in some subjects and only a few months behind in others.

Because retention itself is considered to be the treatment, there is usually no additional effort to correct the lack of teaching and learning that occurred the first time through. In other words, the child may have failed to achieve grade-level standards because the programs or teachers he had were ineffective. Merely repeating the same curriculum or instruction is not likely to fix the problem.

\section{What alternatives are there to retention in grade?}

There are numerous ways to provide extra instructional help focussed on a student's specific learning needs within the context of normal grade promotion. Remedial help, before and after school programs, summer school, instructional aides to work with target children in the regular classroom, and no-cost peer tutoring are all more effective than retention. Unlike retention, each of these solutions has been shown to result in

\section{Accelerated schools: An alternative to holding kids back}

Aside from having students repeat grades, other common strategies designed to help raise achievement among at-risk students include remedial or compensatory services. Another approach is to accelerate student learning, according to Henry Levin. In a report published by CPRE, Levin describes a model of a transitional elementary school designed to bring students up to grade level by the end of sixth grade. The Accelerated School model is being piloted in California, Missouri, Illinois and Utah.

The CPRE report, Accelerated Schools for At-Risk Students, discusses three major assumptions underlying the organization of an Accelerated School: (1) the strategy must enlist a unity of purpose among all of the participants; (2) the strategy must empower all major participants and raise their sense of efficacy and responsibility for school outcomes; and (3) the approach must build on the strengths of the participants rather than criticize their weaknesses.
The entire organization of the Accelerated School focuses on preparing children for the educational mainstream. Intervention is not limited to "pull out" sessions in a school where the main agenda addresses other goals, according to Levin. In addition to the overall structure, the accelerated school also features:

- School-based governancecurriculum, instructional strategies and other school policies are decided by school staff within guidelines set by the district.

- Pupil and school assessment that serves both accountability and diagnostic purposes.

- Substantial parent involvement and training.

- Use of community resources such as social service agencies, volunteer groups and arts and business organizations.

- Extended-day sessions for tutoring, homework, physical activities, etc.

Accelerated Schools for At-Risk Students by Henry Levin (September 1988, 39 pp., No. RR-010, \$4) is available prepaid from CPRE, Eagleton Institute of Politics, Rutgers University, New Brunswick, NJ 08901.

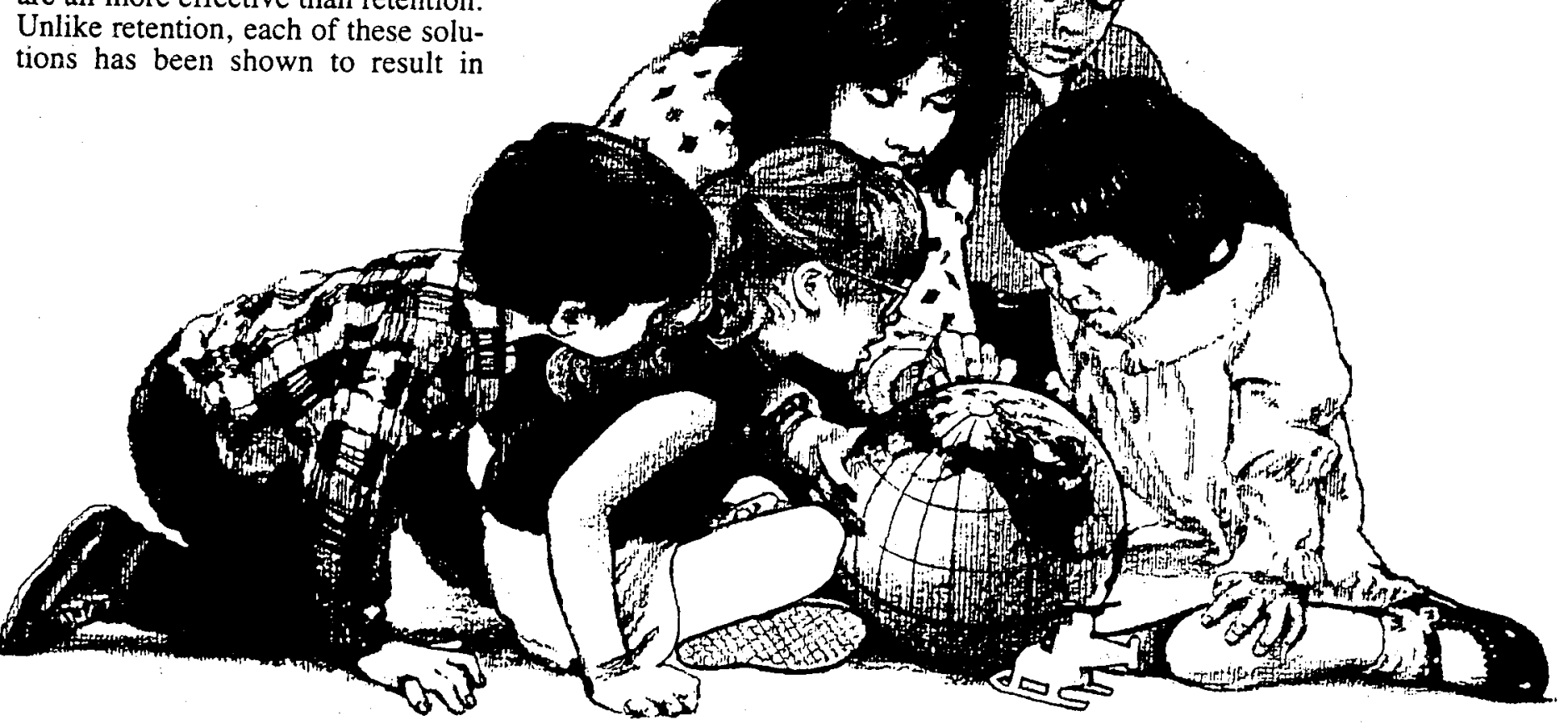


more positive achievement gains for participating children than for controls. Cross-age peer tutoring, for example, where an average 5 th grade student might tutor a 2 nd grader who is behind in math, shows learning gains for both the target students and the tutors.

Educators are also experimenting with alternative structures of schooling and other innovative strategies to meet the needs of those students who are at risk (see sidebar on page 4). These programs should be studied for their potential for improving student achievement.

One of the fears about social promotion is that deficient students will be passed on endlessly as if no one had noticed their problem. Rather than ban retention but do nothing else, creative groups of teachers in a few schools have developed staffing teams (of regular teachers) to work out a plan with the next-grade receiving teacher about how to address the learning difficulties for each student who would have been a retention candidate.

Similarly, some schools "place" poor performing students in the next grade with a formally agreed upon Individualized Educational Plan (IEP) akin to the Special Education model of intervention. The decision to allow a deficient student to advance to the next grade with a plan for special help is analogous to prevalent school policies for gifted students. Instead of skipping academically gifted students one or two grades, schools generally place them in their normal grade and provide them with enriched instruction. Normal grade placement is considered better for them socially and the amount they are ahead is generally not the same in each subject, and not a tidy 12 -month amount. The same arguments can be used to explain why retention does not improve achievement but promotion plus remediation does.

Finally, there is reason to believe that what poorly achieving students need is a more inspired and challenging curriculum, one that involves them in solving meaningful problems, rather than repetitive drill on basic skills. The belief that children have to master component skills before moving on to comprehension and problem solving consigns slow learners to school work that is not only boring but devoid of any connection to the

TABLE 2

\section{Estimated Annual Cost of Grade Retention Nationally}

2.4 million students
retained every year.

$\times \$ 4,051$ per pupil cost. retention in U. S. public schools. (see Table 1). Statistics).
$=\$ 9,722,400,00$

Based on 40 million K-12

enrollment (U.S. Bureau of the Census, 1985) and 6\% annual retention rate

1985-86 average cost per pupil in public elementary and secondary schools. (U. S. Dept. of Education, Center for Education

\section{Nearly $\$ 10$ billion is spent annually on}

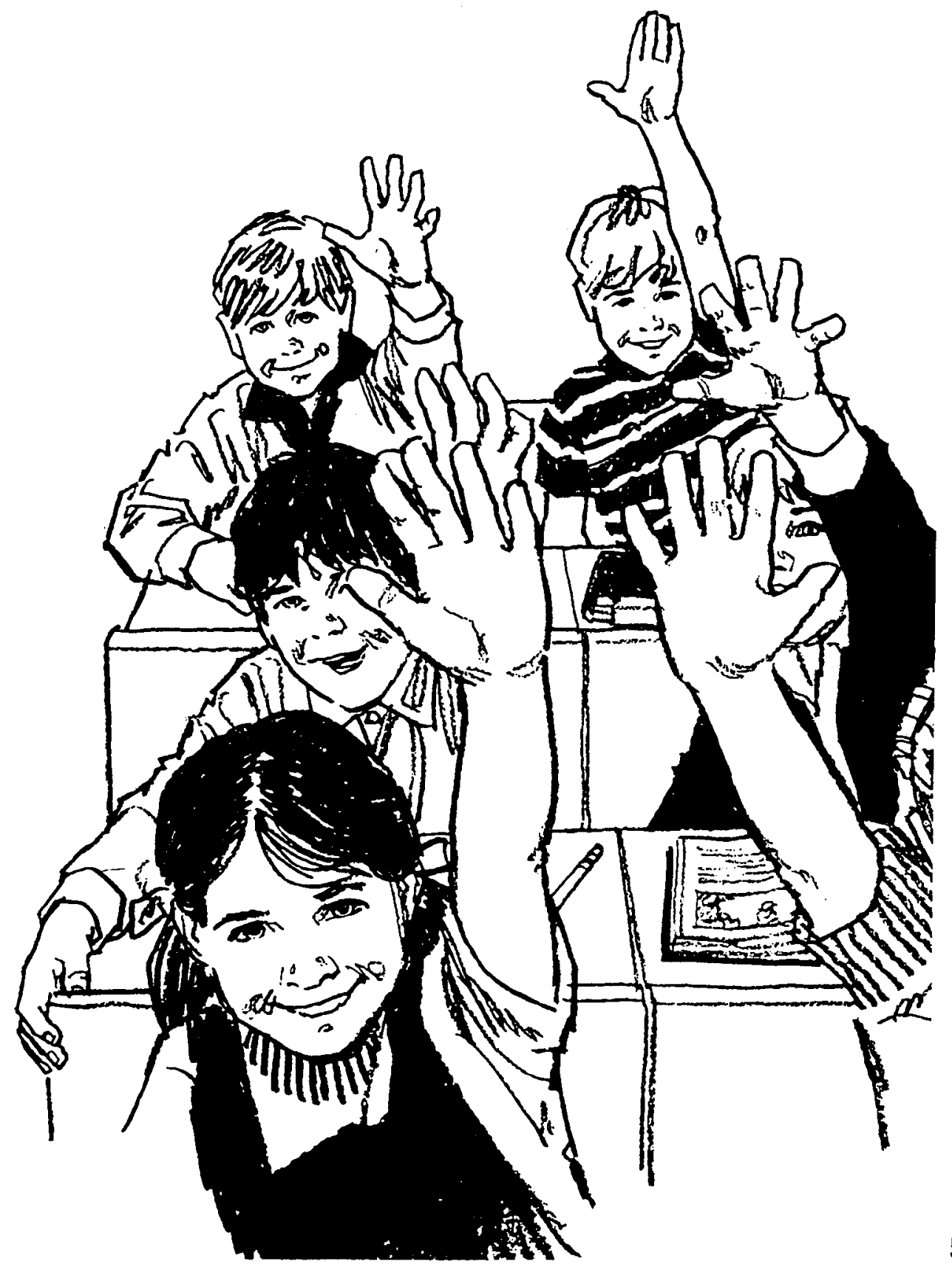


kinds of problems they encounter in the reai world. Furthermore, current learning theory. indicates that skills cannot be learneci effectively nor applied to new problems unless they are learned in context. For example, students who are given lots and lots of problems to solve about how much tile to buy to floor a room with irregular dimensions are likely to be better at both multiplication facts and problem solving than students who must memorize all their multiplication tables before confronting one such problem.

\section{How much does retention cost?}

Collectively, school districts spend nearly $\$ 10$ billion a year to pay for the extra year of schooling necessitated by retaining 2.4 million students. Table 2 provides a summary of the estimated costs of retention each year in the U.S.

Ten billion dollars would support substantial alternative efforts, such as remedial programs, summer school, classroom aides, or reduced class size to help at-risk students learn. For example, summer school costs only approximately $\$ 1300$ per student compared to $\$ 4051$ for a repeated grade.

The costs of retention are not generally clear to policymakers and the public. One reason is that students often move during their years of school. A student spending four years in a district will incur the same costs whether he enrolls in grades 1-2-3-4 or grades $1-2-3-3$. By the time he has moved to his 14th or 15th year of school, he is highly unlikely to live in the same district in which he was retained earlier on. No one jurisdiction bears the cost of retention in such cases.

Therefore, the costs of retention are hidden in the general education budget. In essence, a school simply bills the costs of retaining a child to the state agency in per-pupil costs. The most cost-effective alternative programs, such as tutors or summer school, must be requested and justified as line-item add ons.

\section{What policy implications are suggested by research on retention?}

The research on retention clearly in6 dicates that policymakers and educa- tors should support remediation and other instructional strategies proven to be effective within normal grade placement. Furthermore, current research suggests the value of focusing on curricular reforms that ensure learning by providing opportunities for at-risk students to engage in solving real problems instead of memorizing facts that seem! meaningless.

Since the public so strongly supports retention, broad-based educational efforts addressing the benefits of alternative strategies may be needed. Among the facts the public needs to know is how many students are actually retained currently; it is evident that better data is needed. Only a handful of states collect such data at present.

\section{References}

Byrnes, Deborah A. 1989. "Attitudes of Students, Parents and Educators Toward Repeating a Grade." Pages 180-131 in Shepard and Smith.

Gallup, A. M. 1989. "The 18th Annual Gallup Poll of the Public Attitudes Toward the Public Schools." Phi Delta Kappan 68, 43-59 (September).

Grissom, James B., and Lorrie A. Shepard. 1989. "Repeating and Dropping Out of School." Pages 34-63 in Shepard and Smith.

Holmes, C. Thomas. 1989. Grade-Level Retention Effects: A Meta-Analysis of Research Studies. Pages 34-63 in Shepard and Smith.

Shepard, Lorrie A. 1989. "A Review of Research on Kindergarten Retention." Pages 64-78 in Shepard and Smith.

Shepard, Lorrie A., and Mary Lee Smith (Eds.). 1989. Flunking Grades: Research and Policies on Retention. London: Falmer.

Yamamoto, Kaoru. 1980. "Children Under Stress: The Causes and Cures." Family Weekly, Ogden Standard Examiner, 6-8 (September).

\section{The Center for Policy Research in Education (CPRE)}

CPRE unites four of the nation's leading research institutions in a unique venture to improve the quality of schooling. CPRE conducts research on the implementation and effects of state and local education policies. By communicating its findings to policymakers and practitioners, the Center contributes to the framing of policies to improve education. Members of the CPRE consortium are: Rutgers, The State University of New Jersey; Michigan State University; Stanford University; and the University of Wisconsin-Madison. CPRE is sponsored by the Office of Research in the Department of Education's Office of Educational Research and Improvement (OERI).

\section{CPRE'S}

\section{research activities}

are concentrated in five major areas:

\section{- Curriculum and Student Standards}

- Teacher Policies

- Educational Indicators and Monitoring

- New Roles and Responsibilities

- Evolution of the Reform Movement
In addition to conducting research in these areas, CPRE publishes research reports, briefs and case studies on a variety of education issues. * The Center also sponsors invitational policy workshops for state and local policymakers.

For further information on CPRE, contact: Lynn McFarlane, Assistant Director for Communications, CPRE, Eagleton Institute of Politics, Rutgers-The State University of New Jersey, New Brunswick, NJ 08901; phone (201) 828-3872.

\begin{abstract}
*The views expressed in CPRE publications are those of individual authors and are not necessarily shared by CPRE, its institutional members or the U.S. Department of Education.
\end{abstract}

\section{CPRE Management Director}

Susan Fuhrman

Eagleton Institute of Politics

Rutgers, The State University

of New Jersey

\section{Management Committee}

William Clune

Wisconsin Center for

Education Research

University of Madison-Wisconsin

Richard Elmore

College of Education

Michigan State University

Marshall Smith

School of Education

Stanford University 